\title{
A STATISTICAL ANALYSIS OF VARIATIONS IN HOT TEAR PERFORMANCE AND MICROPOROSITY FORMATION VERSUS COMPOSITION IN INVESTMENT CAST FSX-414
}

\author{
Kevin Ronan ${ }^{1}$ \\ ${ }^{1}$ PCC Structurals Inc.; 4600 SE Harney Drive; Portland, Oregon, 97206, USA
}

Keywords: FSX-414, cobalt, hot tear, microporosity, alloy chemistry, DTA, regression fit model

\begin{abstract}
PCC Structurals Inc. has experienced wide variations in hot tear susceptibility and microporosity formation in industrial gas turbine (IGT) castings poured from different master heats of FSX-414. Each master heat conformed to all specification requirements and foundry control limits. No direct statistical correlation could be identified between alloy chemistry and the occurrence of these casting defects. Empirical data from production castings suggested there to be an inverse relationship between hot tear propensity and microporosity development.

Using data generated from a variety of FSX-414 master heats poured into test vehicle castings, a statistically-significant relationship was established between alloy chemistry and hot tearing by employing regression fit model analyses and by developing an intermediate statistical link with Differential Thermal Analysis (DTA) data generated from each trial casting. Statistically-based connections between alloy chemistry and microstructure were also explored.
\end{abstract}

\section{Introduction}

FSX-414 is an austenitic Co-Cr-Ni-W superalloy which is solid solution strengthened by $\mathrm{M}_{7} \mathrm{C}_{3}, \mathrm{M}_{23} \mathrm{C}_{6}, \mathrm{M}_{6} \mathrm{C}$ and $\mathrm{MC}$ primary carbides. The alloy was developed by the General Electric Company for its hot corrosion resistance and mechanical strength at service temperature as an incremental improvement over alloys $\mathrm{X} 40$ \& X45. The nominal composition of cast FSX-414 is provided in Table I. Although FSX-414 was created more than 40 years ago, it is still widely used in power generation applications today; Precision Castparts Corporation will cast more than $120,000 \mathrm{~kg}$ of FSX-414 in 2008.

The production castings used to develop Figure 1 are large (>40 kg) complex geometry FSX-414 IGT nozzle segments. The same fixed process was used to make each nozzle, from wax molding through casting and post-cast cooling parameters. Based on the fluorescent penetrant inspection (FPI) data presented in Figure 1 , it is evident that there is significant variation in hot tear development between the different alloy master heats. Radiographic inspection of the same castings showed a similar degree of variation in microporosity development. This apparently unpredictable behaviour of the investment casting foundry's two most critical response variables presents an engineering challenge that if not understood and properly managed, could rapidly lead to significant scrap and rework costs.
Microporosity issues in cast FSX-414 must be addressed at the casting level as this alloy does not respond well to hot isostatic pressing (HIP), even at temperatures above $1200^{\circ} \mathrm{C}$. Furthermore, the effects of HIP on the FSX-414 primary carbide microstructure and mechanical properties have not been thoroughly explored. As a result, the use of HIP for the repair of porosity defects in FSX-414 is not accepted practice.

Previous studies conducted at PCC Structurals Inc. (PCC) using production casting data were not able identify a statistically significant link between variations in single element concentration and the propensity of FSX-414 to develop either hot tears or microporosity defects. This suggested that these key response variables were being driven by interactions between alloying elements and/or one or more lurking variables. Reviews of published literature regarding alloying additions made to cast cobalt-base alloys proved to be relevant only for relatively large changes in composition. [1-3,6,7] Although useful, this information is not specific enough to explain the variation in master heat performance that PCC experienced within its band of controlled alloy composition. As a result of this early work, PCC launched a comprehensive study to discover the root of the differences in casting quality which apparently are driven by different FSX-414 master heat chemistries.

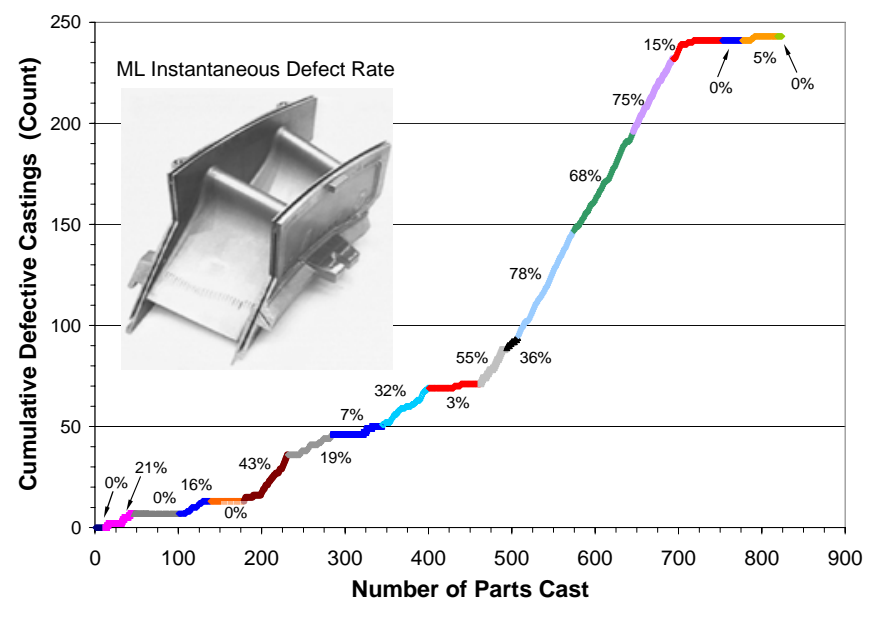

Figure 1. Crow-AMSAA plot of Instantaneous FPI Defect Rate for hot tears in a single location for production FSX-414 IGT nozzle segments. Each series represents a change in metal lot (alloy chemistry). An increase in line slope corresponds to an increase in the instantaneous defect rate.

\begin{tabular}{|c|c|c|c|c|c|c|c|c|c|c|c|}
\hline \multicolumn{10}{|c|}{ Table I. Cast FSX-414 Nominal Chemical Composition (wt. \%) } \\
\hline $\mathrm{C}$ & $\mathrm{Mn}$ & $\mathrm{Si}$ & $\mathrm{P}$ & $\mathrm{S}$ & $\mathrm{Cr}$ & $\mathrm{Ni}$ & $\mathrm{Fe}$ & $\mathrm{W}$ & $\mathrm{B}$ & $\mathrm{Co}$ \\
\hline 0.25 & 0.70 & 0.75 & $0.03 \mathrm{max}$ & $0.02 \mathrm{max}$ & 29.5 & 10.5 & $2.0 \max$ & 7.0 & 0.008 & Balance \\
\hline
\end{tabular}


The short-term goal of this project is to characterize the solidification behaviour of FSX-414 within the boundaries of the PCC IGT investment casting process, the GE Power Systems (GEPS) B50A489 specification for FSX-414 and PCC's established internal chemistry control requirements. The long term goal will be to refine PCC's internal controls for FSX-414 master heat chemistry and tailor castability to establish greater predictability in as-cast IGT castings.

This paper will provide descriptions of the experimental methods, casting results and microstructural evaluations and will outline the development of the statistical analysis approach. Once this foundation is built, the statistically significant relationships discovered between DTA results, hot tears, microporosity and small variations in FSX-414 chemistry will be discussed.

It should be noted that the results presented are specifically relevant to PCC's casting process. Changes in part geometry, investment mold composition, mold preheat temperatures, pouring temperatures and post-cast cooling conditions will all impact solidification kinetics and will therefore affect as-cast part quality. $[5,6]$

\section{Experimental Method}

As a method of reducing experimental confounding due to interactions between casting geometry and part-specific process variables, a simplified test vehicle casting was developed. The Hot Tear Test Vehicle (HTTV) casting shown in Figure 2 consists of a series of six bars of identical thickness attached directly to a central downsprue at the inner ends and risers of identical design at the outboard ends. All fillet radius connections were held constant so as not to induce differences in feeding behaviour or stress development during solidification and cooling.

By employing bars of varying lengths within the HTTV, ranges of mold temperature gradients, solidification strains, cooling strains and requirements for a variety of feeding distances are established within a single mold. The HTTV has the critical benefit of being able to reliably evaluate the effects of each of these variables within a constant chemistry environment. In PCC screen trial experiments, it was shown that the variety of thermal profiles and solidification conditions generated between the different bar lengths provided enough sensitivity to detect differences in solidification behaviour between FSX-414 master heats. [12]

\section{HTTV Production Process}

Over a period of several months, alloy charges from twenty $5,000 \mathrm{~kg}$ production vacuum induction melted (VIM) master heats of FSX-414 were selected at random and set aside. The chemistry of the master heats selected spanned the typical range of foundry control chemistries and also represented a variety of production casting non-destructive evaluation (NDE) results.

The HTTV trial molds used in this investigation were assembled and invested in large batches over a short period of time to reduce the opportunity of confounding experimental results with natural shifts in production processes. All HTTV castings were poured back-to-back over the course of one day using established production casting techniques. The casting campaign for the experiment was batched to help ensure a consistency in post-cast cooling conditions, therefore providing uniform casting cooling rates based on consistent ambient conditions.

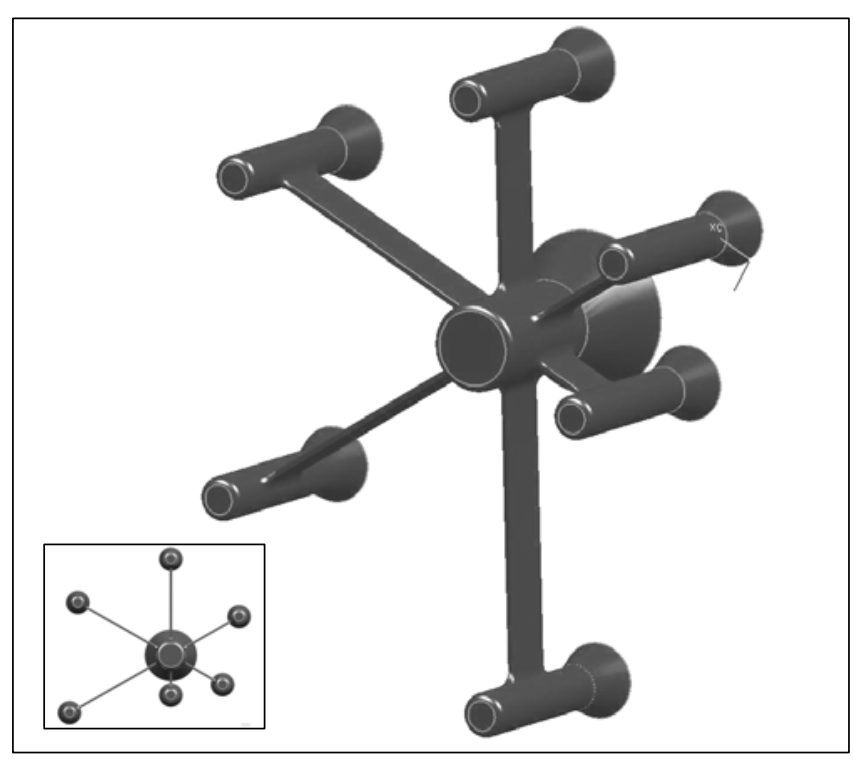

Figure 2. Views of the CAD model definition of the HTTV casting.

\section{Hot Tear Evaluation}

Each HTTV casting was quantitatively evaluated for hot tears using fluorescent penetrant inspection (FPI). FPI data was compiled on the basis of total hot tear length by location for each bar. Although hot tear severity was also established as the product of hot tear length and width, the results proved to be too ambiguous to be of significance.

\section{Microporosity Evaluation}

The four longest HTTV bars were sectioned longitudinally and polished to evaluate microporosity defects. A semi-continuous quantitative rating system was used to objectively evaluate fields of microporosity along the length of each bar. By evaluating the entire length of each sectioned and polished bar at $100 \mathrm{x}$ magnification in a $1 \mathrm{~mm} \times 1.25 \mathrm{~mm}$ field of view (FoV), the semicontinuous microporosity rating (SCMPR) was established as follows:

$$
S C M P R \equiv \sum_{i}(M P \%)_{i} \times L_{i}^{\max }
$$

where $M P \%$ is the maximum percentage of microporosity for each continuous microporosity indication and $L$ is the maximum size of the discrete microporosity field. All fields of microporosity greater than $1 \%$ (surface area) encountered along the length of each sectioned bar were evaluated by quantitative metallographic methods and recorded.

\section{Microstructure Evaluation}

Microstructural characterization of each HTTV casting was completed using the same samples used to establish the SCMPR. Polished mounts were electrolytically etched with $10 \%$ ammonium persulfate to reveal the primary carbide microstructure. Quantitative optical measurements were taken across the entire width of each sectioned bar in three locations: at the bar center, at the inner downsprue fillet radius and at the outer 
riser fillet radius. The following microstructural characteristics were evaluated at each location:

- $\mathrm{M}_{23} \mathrm{C}_{6}, \mathrm{M}_{7} \mathrm{C}_{3}$ and $\mathrm{MC}$ carbide characterization

- Maximum dimensions in FoV

- Total area in FoV

- Secondary dendrite arm spacing

\section{Differential Thermal Analysis}

Two samples for DTA analysis were excised from the same location in each HTTV casting. Each sample was tested against a Pt reference thermocouple at heating and cooling rates of $10^{\circ} \mathrm{C} / \mathrm{min}$ under an inert argon cover set at a flow rate of $100 \mathrm{ml} / \mathrm{min}$. All DTA curves were quantitatively analyzed for each of the heating and cooling events depicted in Figure 3. To lessen the effects of segregation due to the coarse microstructure interacting with the relatively small DTA sample volume, the average of the DTA results from the two curves for each metal lot was used for statistical analysis. [3]

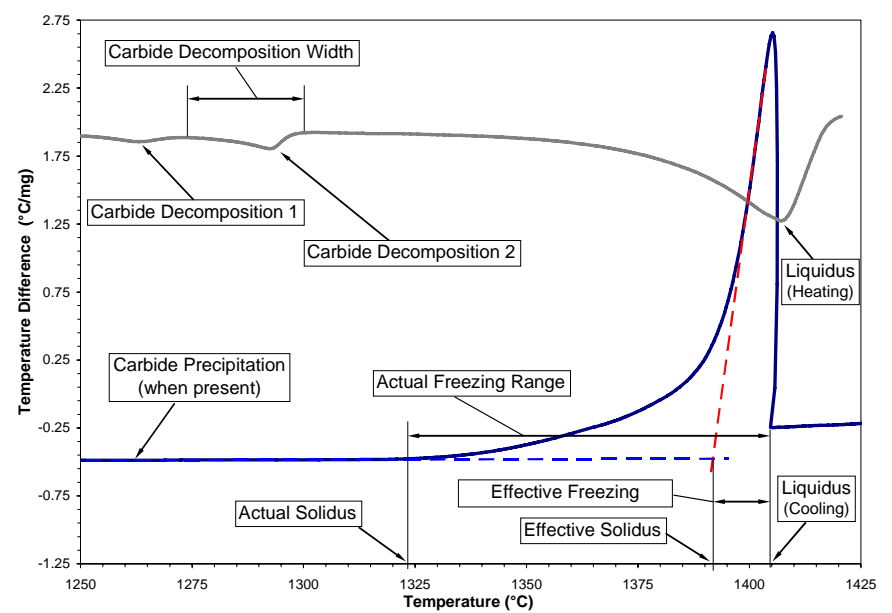

Figure 3. DTA curve quantitative analysis features.

\section{Chemical Analyses}

Chemical analyses of chill samples attached to each HTTV casting were conducted at Cannon-Muskegon Corporation and at BodyCote Materials Testing Laboratory in Portland, Oregon. Both laboratories have extensive experience testing cast FSX-414. Table II lists the analytical method used to test each element that was subsequently used during statistical analysis. Glow Discharge Mass Spectrometry was also conducted at National Analytical Labs on seven HTTV castings to determine whether trace elements were present. None of the trace elements tested showed significant concentrations or adequate variation to warrant the testing of additional castings.

\begin{tabular}{|c|c|c|c|c|c|}
\hline \multicolumn{6}{|c|}{ Table II. Analytical chemistry methods employed. } \\
\hline $\mathbf{C}$ & LECO & $\mathbf{P}$ & $\mathrm{XRF}$ & Al & XRF \\
\hline Mn & XRF & $\mathbf{S}$ & LECO & $\mathrm{Ti}$ & XRF \\
\hline Si & XRF & $\mathrm{Cu}$ & XRF & B & $\mathrm{OE}$ \\
\hline $\mathrm{Cr}$ & XRF & V & XRF & $\mathbf{N}$ & LECO \\
\hline $\mathrm{Ni}$ & XRF & $\mathrm{Nb}$ & XRF & 0 & LECO \\
\hline Mo & XRF & Ta & XRF & & \\
\hline $\mathrm{Fe}$ & XRF & $\mathbf{W}$ & XRF & & \\
\hline
\end{tabular}

Grain Size Evaluation

Over etching of the microstructure samples with $\mathrm{H}_{2} \mathrm{O}_{2}+\mathrm{HCl}$ allowed for macro grain size evaluation. The Heyn mean free path (MFP) evaluation method was used to determine the average grain size for the cross section of each bar. MFP grain size was calculated at the bar center and at each fillet radius.

\section{Casting Analysis \& Metallographic Observations}

Test Vehicle Hot Tear Results

The HTTV castings showed similar variations in hot tear performance and microporosity severity in comparison to production casting results. All hot tear defects occurred at one or both of the inner downsprue or outer riser fillet radii. As illustrated in Figure 5, bars from some metal lots tore so severely that complete dissociation of the bar and outer riser was achieved.

Each HTTV hot tear was located in or adjacent to the fillet radii; the portions of the bars that were last to solidify. Necking across the width of the cast bar was observed in only a few of the most severe hot tears. In all cases, hot tears progressed along grain boundaries and the surfaces of the tears were decorated heavily with $\mathrm{M}_{23} \mathrm{C}_{6}$ carbides. The consistent presence of eutectic carbide at the hot tears supports the concept of these defects developing very late in the solidification process. Figure 4 provides examples of the range of hot tear severity and Figure 6 illustrates the typical microstructure observed along hot tears.

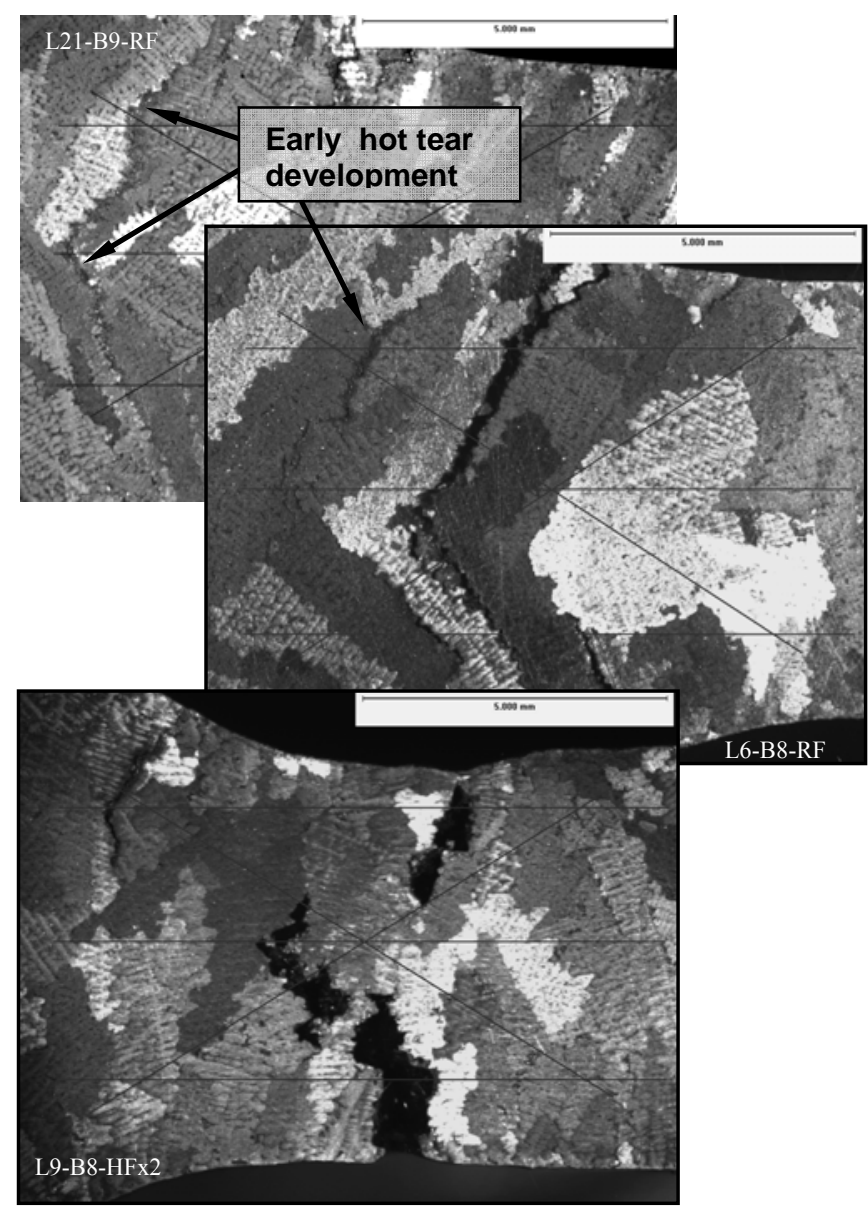

Figure 4. Examples of the range of hot tear development and severity. 

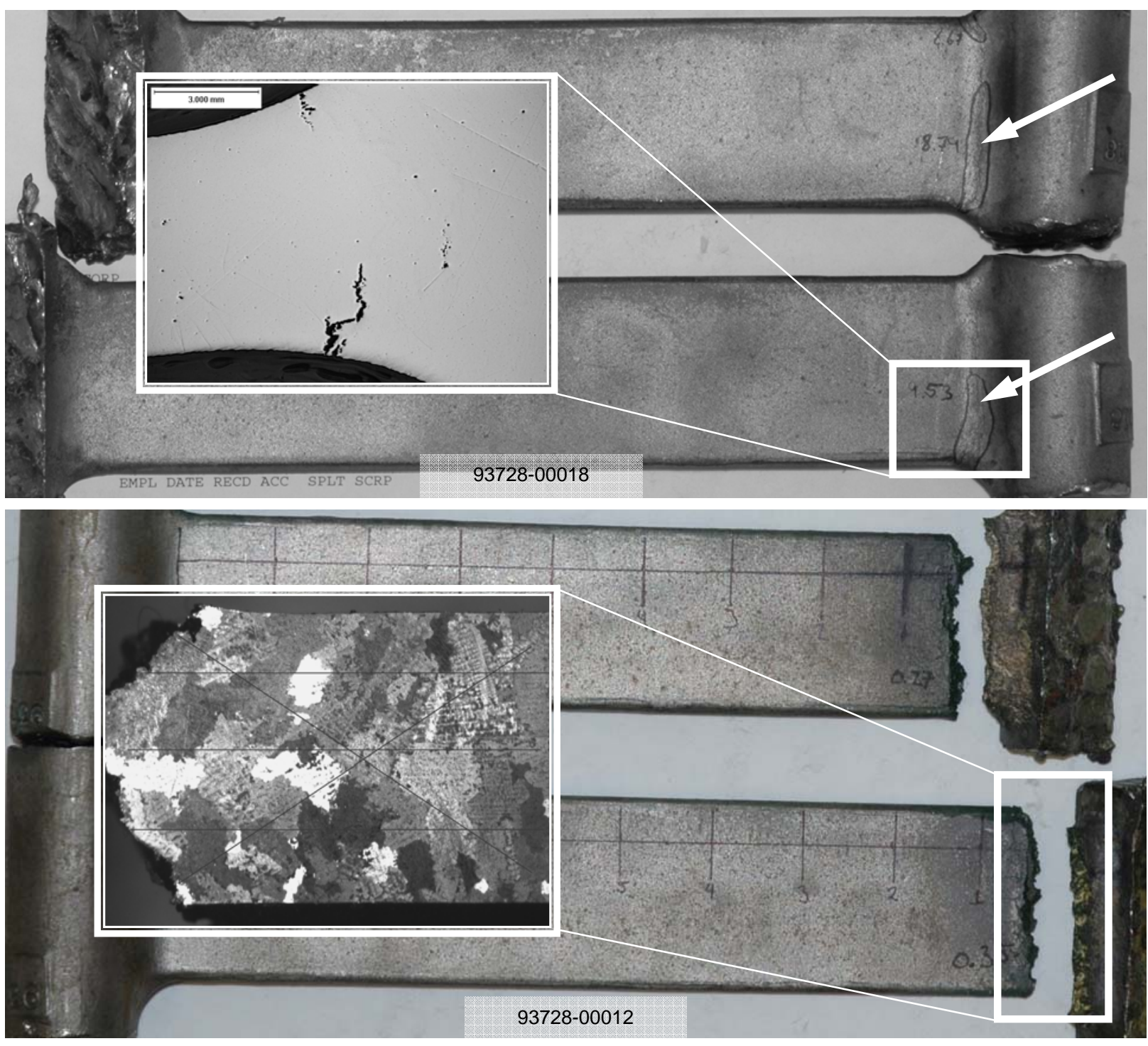

Figure 5. Examples of the differences in hot tear susceptibility between metal lots for HTTV bars of identical length. In some cases, complete dissociation of the cast bar was observed.

Microporosity Results

Microporosity results varied between HTTV castings. The micrographs in Figure 7 were taken in similar locations from two bars of identical length and show a range of microporosity developed between master heats. For those metal lots that were prone to more severe microporosity defects, the fields of porosity were most often layered and corresponded to the longer freezing range metal lots.

Hot Tearing versus Microporosity Development

In published literature, there are several different explanations of how microporosity develops. Campbell's approach clearly describes the formation layer porosity while maintaining a link to dynamic solidification stresses. In his description of layer porosity, Campbell contends that the hydrostatic tension in the solidifying liquid increases through the mushy zone. As solidification moves toward completion, the local stress in the remaining liquid increases to a threshold value and forms a pore.
The pores spread along isobaric, and likely isothermal, surfaces through the interdendritic passages. When a layer of porosity is created, local hydrostatic tension in the remaining liquid is relieved. As solidification progresses along the casting, this process repeats, thus forming additional layers of porosity. [5]

Using Campbell's explanation, the relief of solidification stresses through the formation of porosity is clearly responsible for the inverse relationship between hot tearing and microporosity formation; a phenomenon that PCC experienced in production IGT castings and again confirmed in HTTV castings. Figure 8 illustrates this inverse relationship for HTTV castings and also shows multiple microporosity relationships. The solid trend line for microporosity depicts a regression fit to all of the SCMPR data. However if the SCMPR data is separated into two groups, more statistically significant fits to the microporosity data become apparent. All of these trends support inverse relationships between microporosity and hot tearing. 

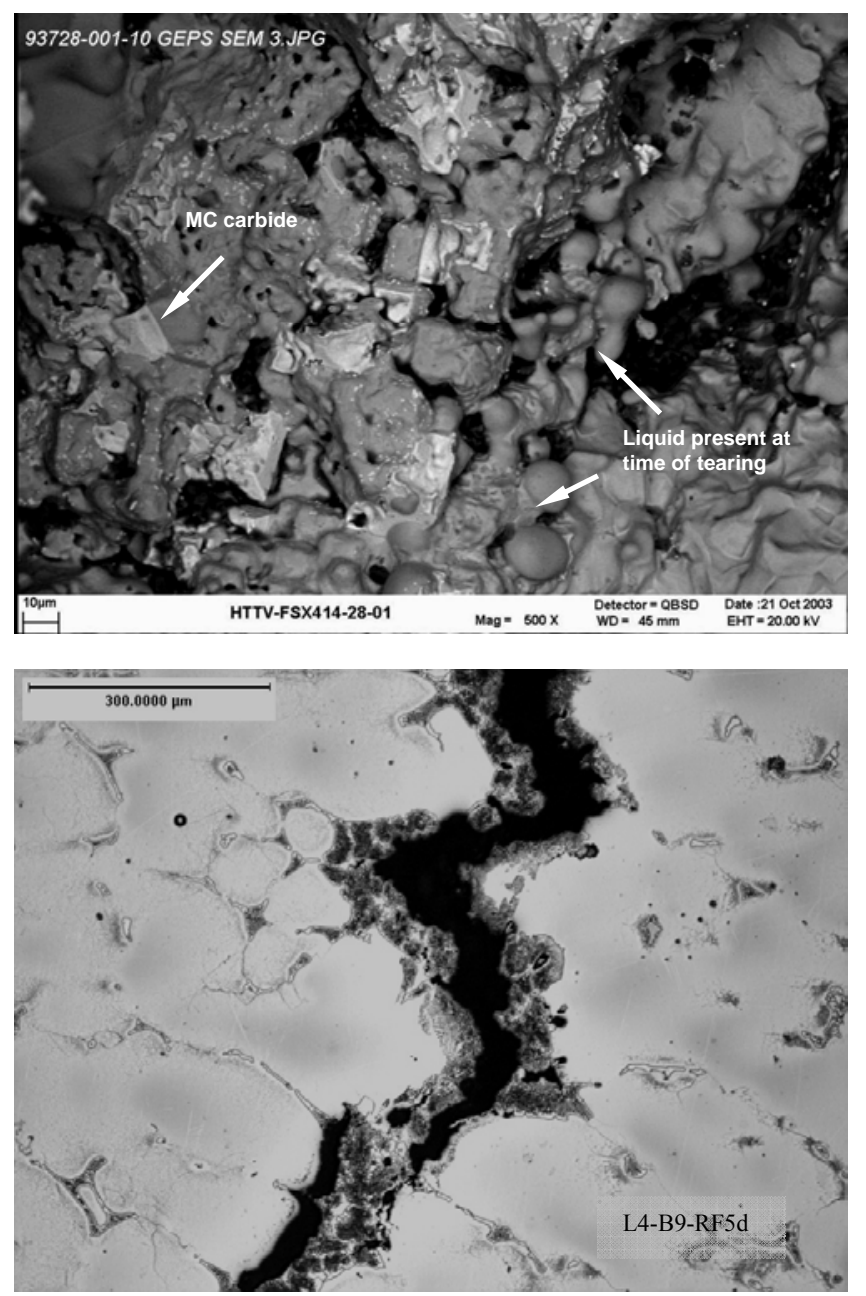

Figure 6. Typical carbide decoration of hot tear surfaces.
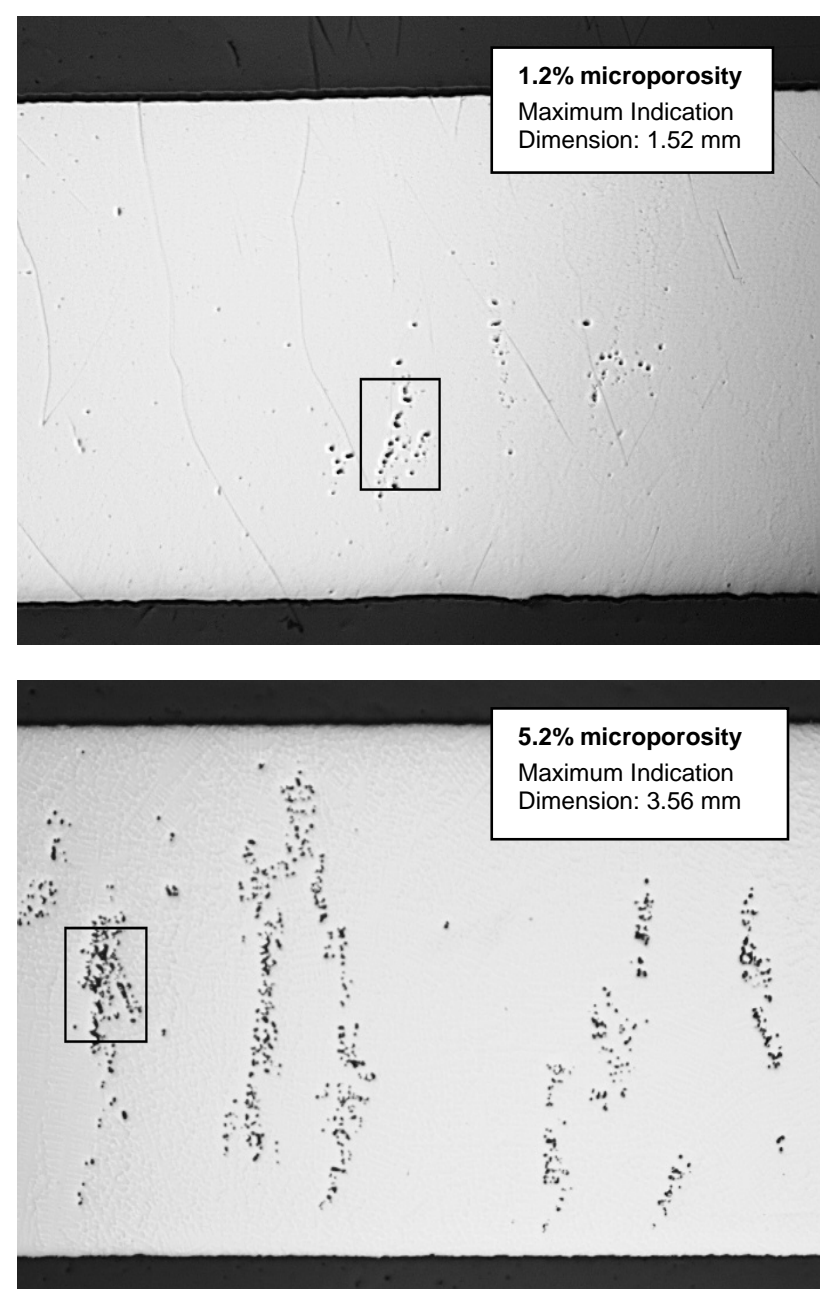

Figure 7. Examples of the differences in microporosity development between metal lots for HTTV bars of identical length.

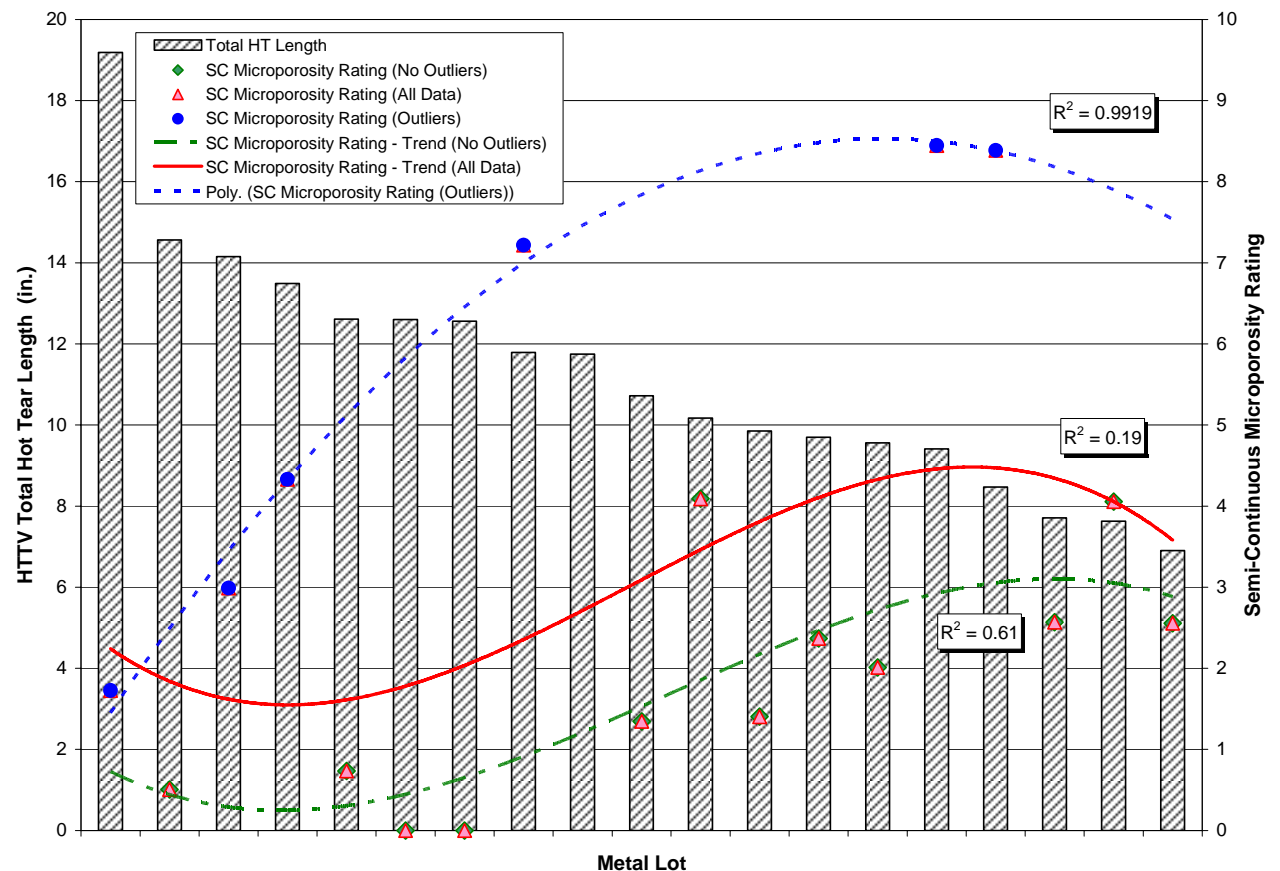

Figure 8. HTTV hot tear performance versus semi-continuous microporosity rating. 
DTA Results

The DTA results from the HTTV castings confirmed the macroscopic and microscopic responses discussed so far: there are perceptible differences in alloy solidification behaviours from master heat to master heat although each heat conforms to all chemistry specification requirements and foundry control limits. Figures 9 and 10 show a number of HTTV DTA heating and cooling curves plotted together. The curves have been shifted in the y-axis to clearly illustrate the variation in event temperatures.

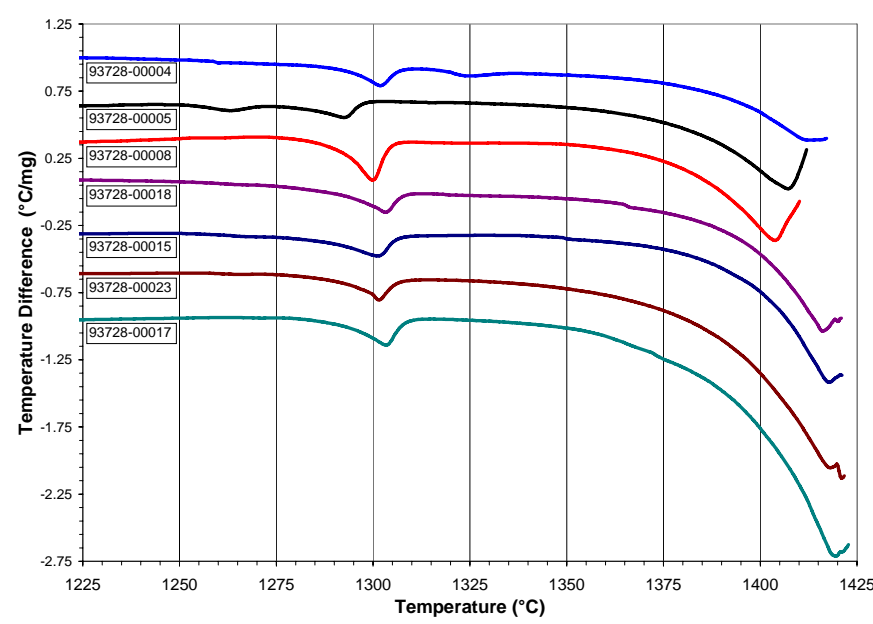

Figure 9. Sample of HTTV DTA heating curves.

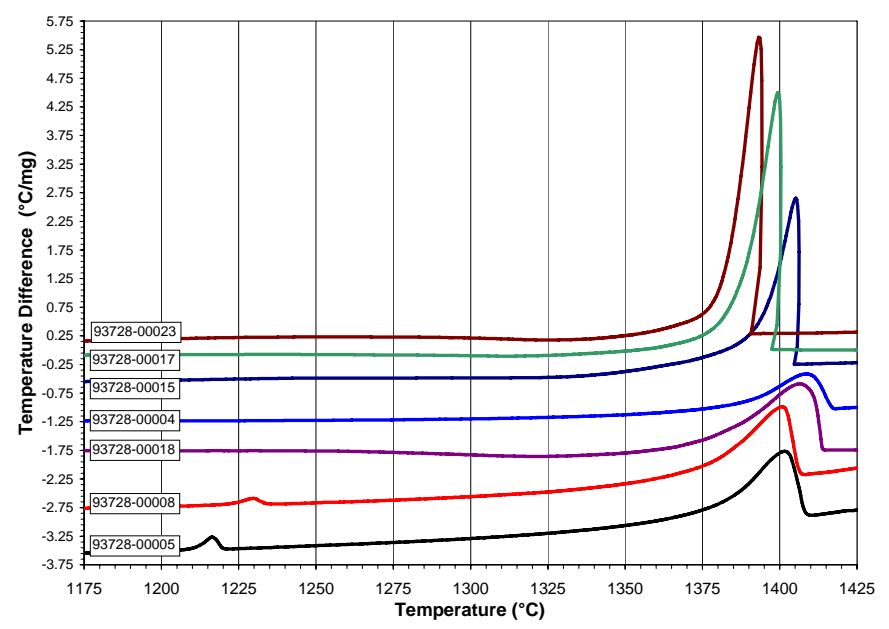

Figure 10. Sample of HTTV DTA cooling curves.

The shifts in liquidus, solidus and carbide decomposition event temperatures can be tied to changes in eutectic composition. [9] It is important to note the differences in the intensity of each event as the area under each curve defines the enthalpy $(\Delta \mathrm{H})$ of the event. The slope of the event curves relate to the rate at which the event proceeds. [4]

Casting Results \& Observations Summary

Based on the variety of results observed over multiple response variables throughout the HTTV population, it is conceivable that statistical analysis may show significance within the trial results. This hypothesis will now be explored and tested.

\section{Statistical Analysis Results \& Discussion}

Even with the variety of results experienced within the HTTV trials, PCC's experience with single-element interactions versus key response variables in production castings was confirmed; no statistically significant correlation could be established. As an example, Figure 11 shows the most significant regression fit of HTTV hot tears versus changes in single element concentration.

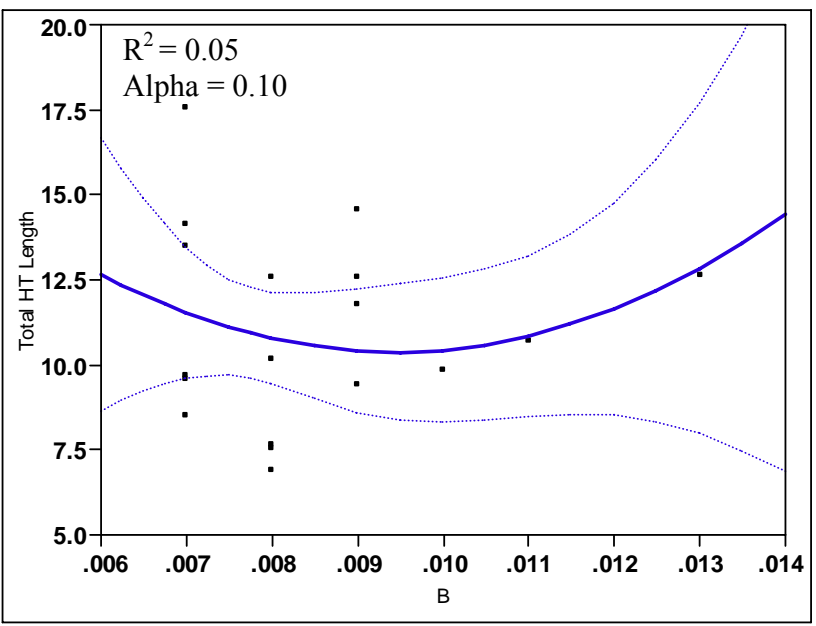

Figure 11. Regression analysis of hot tear length versus boron concentration in HTTV castings.

The HTTV confirmation of production analyses makes it clear that the relationships between predictor or " $X$ " variables and the response or "Y" variables are complicated. In order to evaluate all potential X's as they relate to a Y variable like hot tear susceptibility, the $\mathrm{JMP}^{\mathrm{TM}}$ Fit Model analysis platform was selected. The Fit Model takes all regressed X variables out of what would otherwise be the noise or error term in a bivariate i.e. single variable regression analysis similar to the one shown in Figure 11, and evaluates each of their linear regression equations simultaneously. In so doing, all variables are regressed and their individual variation considered at the same time. In using this powerful statistical tool, care must be taken to ensure that tightly correlated X's are not used within the same model. [10,11]

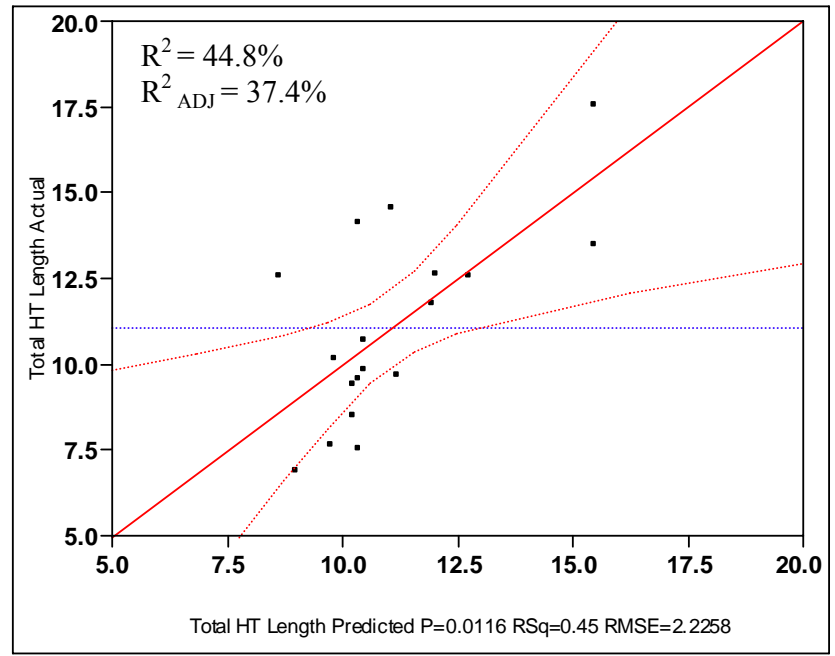

Figure 12. Fit model analysis of hot tear length versus Si \& W. 
Figure 12 illustrates the fit model results of chemistry versus HTTV hot hear performance. In this analysis, only Si and W were established to be statistically significant contributors to hot tearing. The regression fit is marginally significant and does not directly explain the variation in FSX-414 castings presented above. Considering that it may be impossible to establish a straight forward relationship between alloy chemistry and hot tearing, it becomes evident that an alternate approach is necessary.

\section{Approach: Progressive Statistical Link}

The driving forces behind the development of hot tears and microporosity defects are rooted in the fundamentals of solidification theory, thermodynamics and phase transformations. Many of the thermodynamic and solidification events, e.g. undercooling through the liquidus temperature and the formation of primary and secondary dendrite arms, take place in advance of the formation of microporosity or hot tear defects. In many respects, microporosity defects and hot tears are merely the end result of an enormously complicated process, resultants of the interaction of myriad variables in the complex and chemically interactive investment casting system.

In light of these considerations, a progressive analytical approach was attempted. As DTA data summarizes many of the thermodynamic and solidification events discussed above, establishing a link between hot tear propensity and DTA data seemed to be a logical first step. Figure 13 shows the statistically significant results of this analysis.

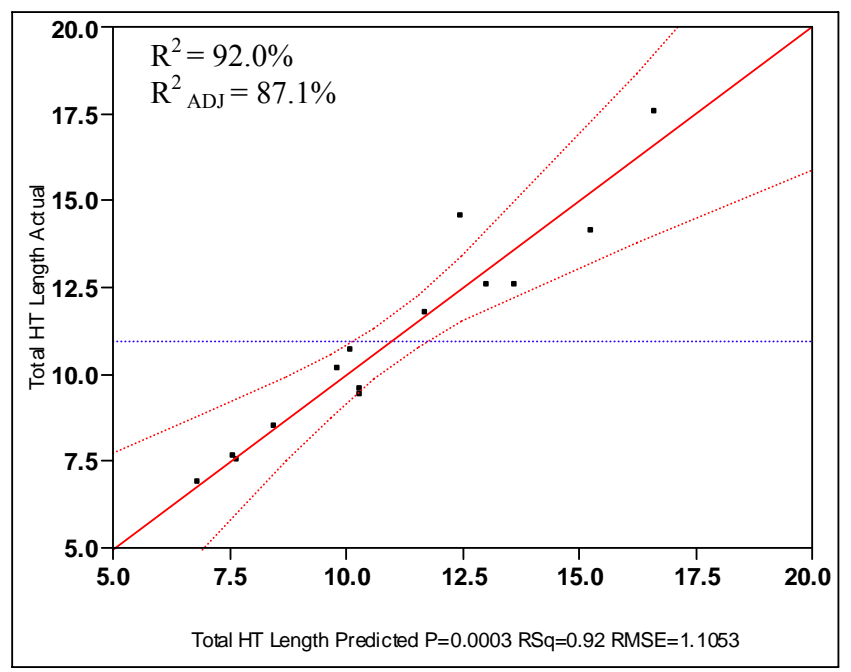

\begin{tabular}{|l|r|r|r|r|}
\hline Term & \multicolumn{1}{c}{ Estimate } & \multicolumn{1}{c|}{ Std Error } & \multicolumn{1}{c|}{ Ratio } & Prob $>|t|$ \\
\hline Intercept & -288.9328 & 47.81505 & -6.04 & 0.0003 \\
Melting Curve - Carbide Decomp 2 Width & -0.08838 & 0.037714 & -2.34 & 0.0472 \\
Solid'n Curve - Liquidus & -0.191314 & 0.039119 & -4.89 & 0.0012 \\
Solid'n Curve Effective Solidus & 0.3082338 & 0.051471 & 5.99 & 0.0003 \\
Melting Curve - Carbide Decomp 1 & -0.151015 & 0.06414 & -2.35 & 0.0464 \\
Melting Curve - Carbide Decomp 2 Start & 0.2646998 & 0.063006 & 4.20 & 0.0030 \\
\hline
\end{tabular}

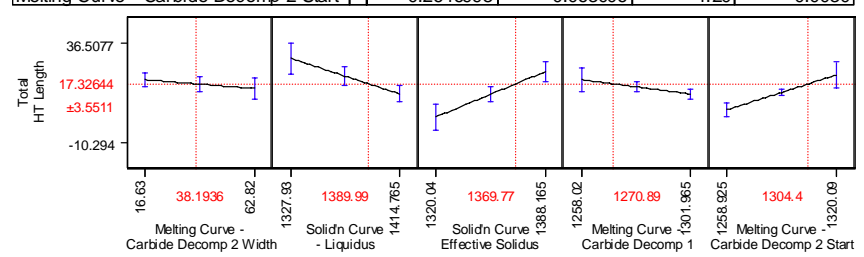

Figure 13. Fit model analysis of hot tear length versus DTA data, including parameter estimates of significant terms and prediction profile.
Microstructural Fit Models

Efforts were made to establish statistical significance between hot tear propensity and the quantitative microstructural data collected. In order to increase the likelihood for statistical significance, the experimental data was broken into its discrete components by location, thus allowing the fit model platform the opportunity to consider as much variation within the model as possible. With $\mathrm{R}_{\text {ADJ }}^{2}=77.1 \%$, Figure 14 shows a relatively good fit model result for hot tear length at the downsprue end of the longest HTTV bar versus microstructural responses. However, the regression fit falls well below $\mathrm{R}^{2}{ }_{\mathrm{ADJ}}=50 \%$ when both ends of the bar are considered together, or if the outer riser bar end data is regressed on its own.

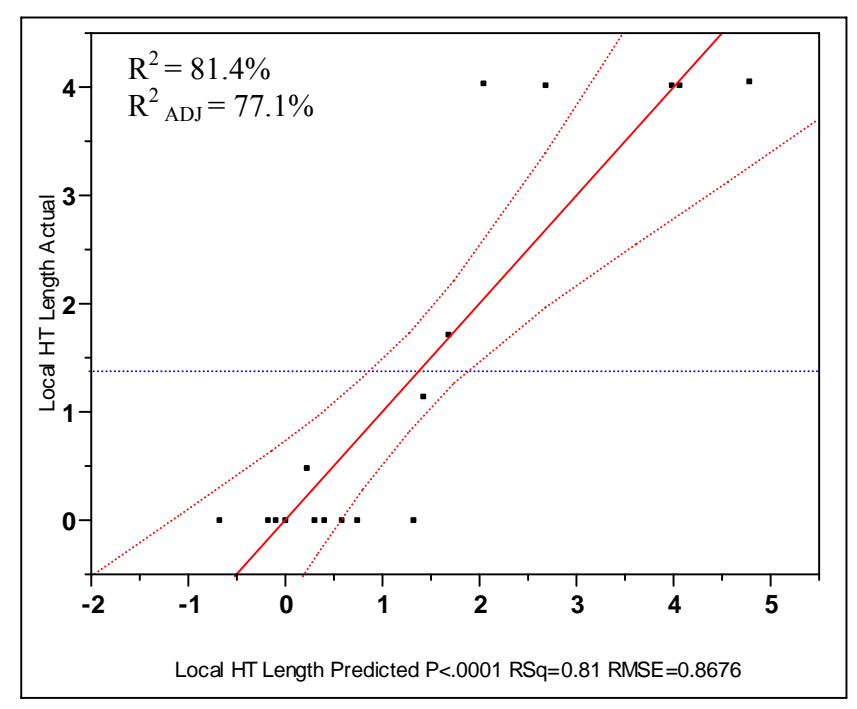

\begin{tabular}{|l|r|r|r|r|}
\hline Term & \multicolumn{1}{c}{ Estimate } & Std Error $\boldsymbol{t}$ Ratio & Prob $>|t|$ \\
\hline Intercept & -3.019957 & 0.86094 & -3.51 & 0.0039 \\
MFP Grain Size & 3.1339289 & 1.078912 & 2.90 & 0.0123 \\
Sum Area M26C6 FOV $(\mu \mathrm{m} 2)$ & 0.0000357 & 0.000012 & 2.93 & 0.0117 \\
Sum M7C3 Area FOV $(\mu \mathrm{m} 2)$ & 0.0000382 & 0.000009 & 4.18 & 0.0011 \\
\hline
\end{tabular}

Figure 14. Fit model analysis and parameter estimates for hot tears versus microstructural responses; longest HTTV bar at the downsprue.

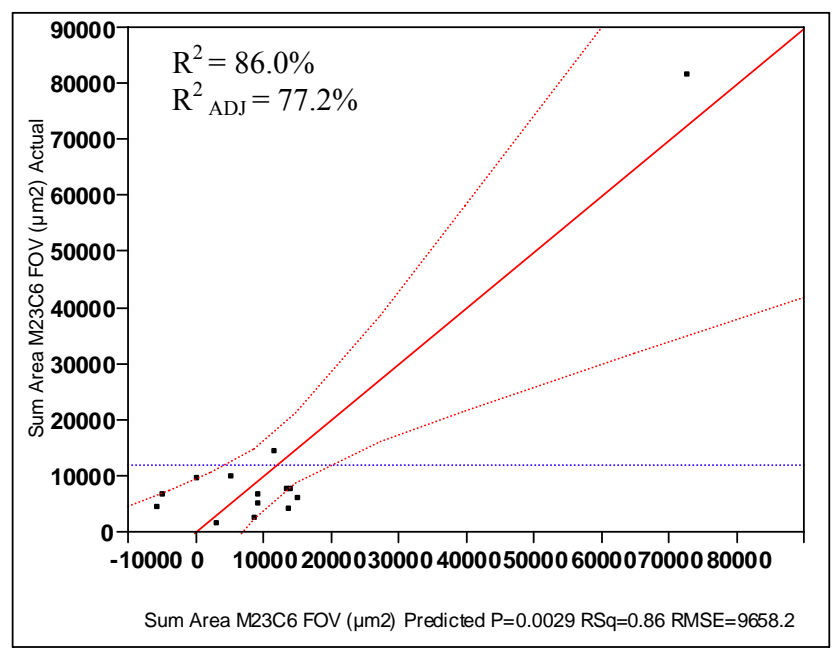

Figure 15. Fit model analysis of total $\mathrm{M}_{23} \mathrm{C}_{6}$ carbide area versus DTA data; HTTV longest bar downsprue fillet. 
Similar situations were experienced when regressing microstructural responses with DTA results. Figure 15 shows a highly significant fit for total $\mathrm{M}_{23} \mathrm{C}_{6}$ carbide area at the downsprue end of the longest HTTV bar. The strength of this regression fit hinges upon a single HTTV lot that when removed from the analysis, causes the entire regression model to become statistically insignificant. $\mathrm{M}_{7} \mathrm{C}_{3}$ carbide area at the downsprue provides a slightly more stable fit with DTA results but is still subject to a similar single lot dependency as $\mathrm{M}_{23} \mathrm{C}_{6}$.

Establishing links between the metallographic responses and hot tear propensity proved to be difficult for the following reasons:

1. Performing a statistical analysis of hot tearing versus all available microstructural data is inherently confounded with bar length; each bar will have a different propensity for tearing as a function of its length. As the bars shorten, null hot tear length data becomes increasingly prevalent. In addition to being intuitively obvious from a metallurgical perspective, it was also apparent during the evaluation of the microstructural samples that a lack of hot tears in the shorter bars did not correspond with highly significant changes in cast microstructure.

2. Figure 16 shows a scanning electron microscope (SEM) backscatter image of a grain boundary carbide which optically, appears to be $\mathrm{M}_{23} \mathrm{C}_{6}$. The SEM backscatter image and maps show more dense regions within the carbide which correspond with high local concentrations of $\mathrm{W}$ and $\mathrm{Ta}$, both known to be strong formers of $\mathrm{M}_{6} \mathrm{C}$ carbides in Co-base superalloys. [2,5] Correctly determining the difference between $\mathrm{M}_{23} \mathrm{C}_{6}$ and $\mathrm{M}_{6} \mathrm{C}$ carbide structures is very difficult, if not impossible, using optical microscopy. The ambiguity in optical differentiation of these two important carbides lends uncertainty to the statistical analysis.

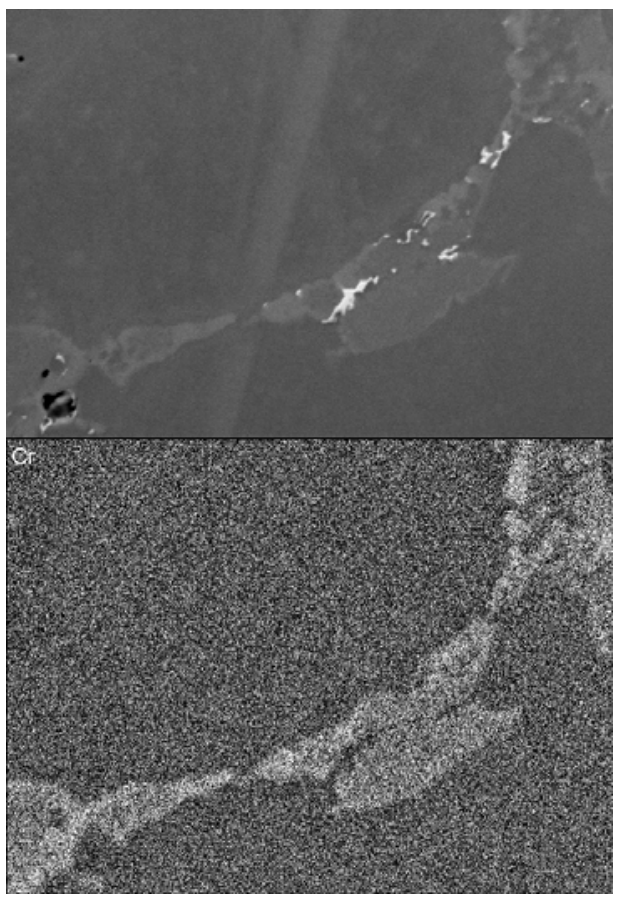

Figure 16. SEM backscatter image, $\mathrm{Cr}$ map of grain boundary carbide.
3. Although a great deal of continuous microstructural data was compiled, it is not representative of the macroscopic responses. The microstructure data was evaluated in multiple fields of view at three locations along the bar length. This equates to at most, a $1 \mathrm{~mm}$ wide band of microstructural evaluation in each location. Even if summed, this represents only $0.6 \%-1.2 \%$ of the total length of the bars that exhibited hot tears. The MFP macro grain size evaluation is perhaps the only representative microstructural measurement as it is evaluated over a comparatively large surface area.

\section{Chemistry Fit Models}

Very strong statistical links between chemistry and DTA events were discovered using the HTTV data. The average $\mathrm{R}^{2}$ value for the statistically significant fit models for the events detailed in

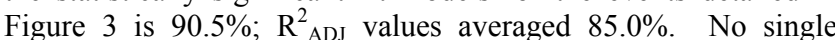
HTTV lot dependencies were detected in any of the chemistry versus DTA event models. Figure 17 shows an example of the exceptionally strong fit model results for chemistry. Table 3 summarizes all of the chemistry versus DTA fit model analyses.

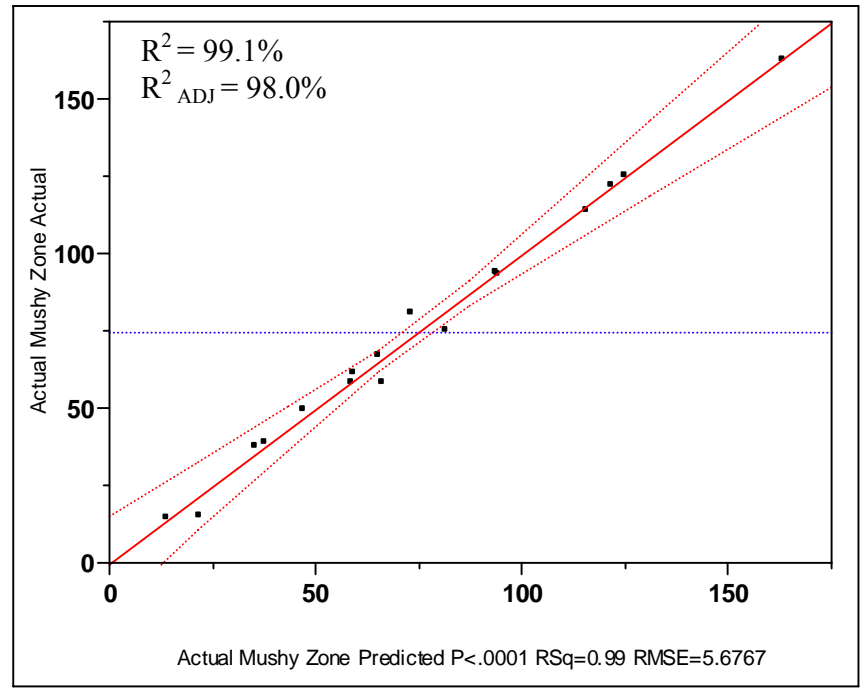

Figure 17. Fit model analysis of Actual Solidification Range versus HTTV chemistry results.

Statistical Analysis Summary

Although the results summarized in Table III are specific to the PCC casting process, they are also supported by the accepted role(s) of each element in Co-base superalloy metallurgy which are summarized in Table IV. [1-3,7,8]

It is important to note when evaluating the results in Table III that elements not part of the specification controls for FSX-414 played a statistically significant role in modifying the solidification behaviour of the alloy. This compounds the interactive effects of specification controlled elements which themselves need to have new control limits implemented in order to reduce production casting variability.

With strong statistical links having been established between chemistry and DTA results, a complete picture of the HTTV behaviour can be drawn. Figure 18 describes pictorially, the connection achieved between the macroscopic response variables and small variations in FSX-414 alloy chemistry. 


\begin{tabular}{|c|c|c|c|c|c|c|c|c|c|c|c|}
\hline & & 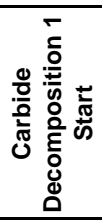 & 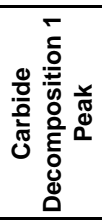 & 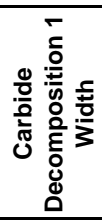 & 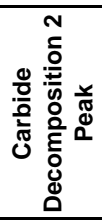 & 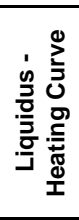 & 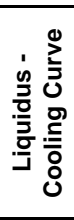 & 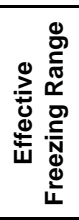 & 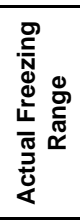 & 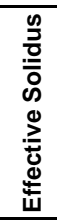 & 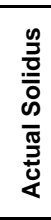 \\
\hline \multirow{16}{*}{ 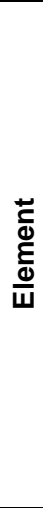 } & C & & & & 1 & 1 & & & & & \\
\hline & $\mathrm{Mn}$ & & & & & 1 & & & 1 & & 1 \\
\hline & Si & 1 & 1 & & 1 & & & & 1 & & \\
\hline & $\mathrm{Cr}$ & & & & 1 & 1 & 2 & 2 & 1 & 2 & \\
\hline & $\mathrm{Ni}$ & & & 1 & & & 2 & 2 & & 1 & \\
\hline & Mo & 1 & & & & & 1 & 1 & 1 & 1 & \\
\hline & $\mathrm{Fe}$ & & & 1 & 2 & & 2 & 1 & 1 & 1 & 1 \\
\hline & $P$ & & & & & & & & 1 & & 1 \\
\hline & $\mathbf{S}$ & & & & & & & 1 & & & \\
\hline & $\mathrm{Cu}$ & & & & & 1 & & & & & \\
\hline & $\mathrm{V}$ & & & & & 1 & & & & & \\
\hline & $\mathrm{Nb}$ & & & 1 & & & & & 1 & & 1 \\
\hline & $\mathbf{W}$ & 1 & 2 & & 2 & & & & 1 & 2 & \\
\hline & Al & 2 & 1 & 1 & & 1 & & & 1 & & \\
\hline & $\mathrm{Ti}$ & 2 & 2 & & & 1 & & & & & \\
\hline & B & & & & & 1 & & & & & \\
\hline \multirow{2}{*}{\multicolumn{2}{|c|}{$\begin{array}{c}\text { R Sq. (\%) } \\
\text { R Sq. Adj. (\%) }\end{array}$}} & 92.8 & 96.8 & 83 & 89.4 & 90.8 & 90.4 & 88.2 & 99.1 & 90.9 & 84.3 \\
\hline & & 86.6 & 94.9 & 75.5 & 83.1 & 81.6 & 84.6 & 81.1 & 98.0 & 85.5 & 79.1 \\
\hline
\end{tabular}

Table III. Summary of chemistry versus DTA fit model analyses. Elements participating in the fit model are indicated by the highest order interaction with which they participated in the overall model.

\begin{tabular}{|c|c|c|c|c|c|c|c|c|c|c|}
\hline 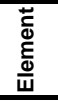 & $\begin{array}{c}\text { Increase } \\
\text { Solidification } \\
\text { Range }\end{array}$ & $\begin{array}{l}\text { Solid Solution } \\
\text { Strengthener }\end{array}$ & $\begin{array}{c}\text { HCP } \\
\text { Stabilizer }\end{array}$ & $\begin{array}{c}\text { FCC } \\
\text { Stabilizer }\end{array}$ & MC & $\mathrm{M}_{6} \mathrm{C}$ & $\mathrm{M}_{7} \mathrm{C}_{3}$ & $\mathrm{M}_{23} \mathrm{C}_{6}$ & $\begin{array}{l}\text { Rupture } \\
\text { Strength } \\
\text { Increase }\end{array}$ & $\begin{array}{c}\text { Forms } \\
\text { Intermetallics }\end{array}$ \\
\hline C & & & & $x$ & $x$ & $x$ & $x$ & $x$ & & \\
\hline $\mathrm{Cr}$ & & & $x$ & & & & $x$ & $x$ & & \\
\hline $\mathrm{Ni}$ & & & & $x$ & & & & & & NiзTi \\
\hline $\mathrm{Fe}$ & & & & $x$ & & & & & & \\
\hline B & & & & & & & & & $x$ & \\
\hline $\mathrm{Zr}$ & & $x$ & & & $x$ & $x$ & & & $x$ & CoзZr \\
\hline Hf & & $x$ & & & $x$ & $x$ & & & & $\mathrm{Co} 3 \mathrm{Hf}$ \\
\hline V & & $x$ & & & $x$ & $x$ & & & & Соз $\mathrm{V}$ \\
\hline Al & & & & & & & & & & CoAl \\
\hline $\mathrm{Ti}$ & & & & & $\mathrm{x}$ & & & & & $(\mathrm{Co}, \mathrm{Ni}) 3 \mathrm{Ti}$ \\
\hline Mn & & & & $\mathrm{x}$ & & & & & & \\
\hline Si & $x$ & & & & & & & & & $\begin{array}{l}\text { Laves phase above } \\
\text { solubility limit }\end{array}$ \\
\hline Mo & $\mathrm{x}$ & & $x$ & & & $x$ & & & & СозМо \\
\hline W & & & $x$ & & & $x$ & & & & $\mathrm{Cos} \mathrm{W}$ \\
\hline $\mathrm{Ta}$ & $x$ & $x$ & & & $x$ & $x$ & & & & СозТа \\
\hline $\mathrm{Nb}$ & $x$ & $x$ & & & $x$ & $x$ & & & & Соз $\mathrm{Nb}$ \\
\hline
\end{tabular}

Table IV. Alloying effects and carbide composition components in heat-resistant Co-based superalloys. [1,2]
$61 \%<\mathrm{R}_{\mathrm{ADI}}^{2}<99 \%$
$\mathrm{R}_{\mathrm{ADJ}}^{2}=87 \%$
$\overline{\mathrm{R}}_{\mathrm{ADJ}}=85 \%$

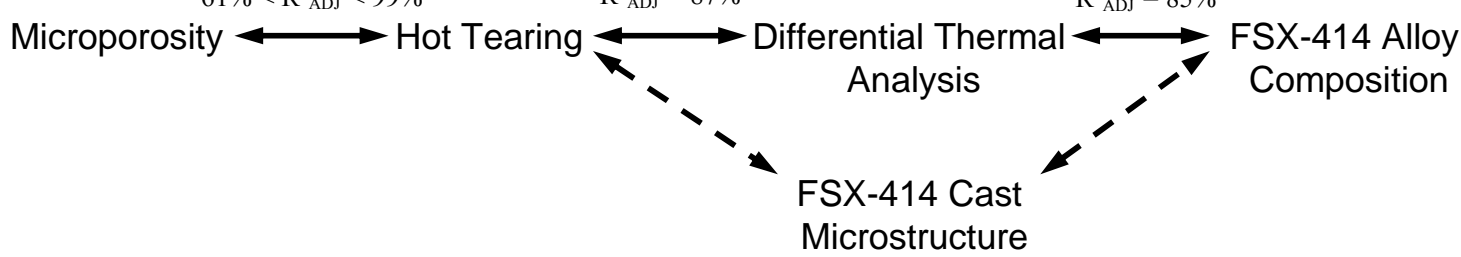

Figure 18. Connection map and regression fits between FSX-414 chemistry and the macro- and microscopic response variables. 


\section{Conclusions}

1. There is a statistically significant inverse relationship between microporosity development and hot tear susceptibility in investment cast FSX-414.

2. Straight forward statistical relationships between small variations in chemistry and hot tearing or microporosity development cannot be determined for cast FSX-414.

3. Fit model (co-variation) analyses are instrumental in developing a thorough understanding of FSX-414 casting variability with respect to alloy chemistry.

4. The macroscopic responses of hot tear susceptibility and microporosity development can be linked to small variations in chemistry through an intermediate fit with DTA data.

5. First- and second-order interactions of elements must be considered in order to develop an understanding of how small variations in FSX-414 chemistry affect hot tearing and microporosity development.

6. Elements outside the GEPS FSX-414 B50A489 specification range and the existing PCC foundry control limits affect the as-cast quality of FSX-414 IGT castings at PCC.

7. Without refined tailoring of elemental interactions, it is possible to engineer the creation of casting defects within the specification range of FSX-414.

8. The coarse microstructure of FSX-414 is not well suited to intensive statistical analysis even if analyzed quantitatively unless the total microstructural area evaluated is significant in comparison to the overall size of the sample.

\section{Future Work}

Future work will include the definition and validation of refined alloy chemistry targets for cast FSX-414. The first steps will likely include thermodynamic verification of the results presented in this paper as well as thermodynamic and/or practical validation of the proposed chemistry targets. Additional DTA, DSC, electrothermomechanical testing and/or Gleeble testing of cast FSX-414 samples will also be helpful to build a more thorough understanding of solidification events. Further exploration of the driving force behind what appears to be two different trends in microporosity development is also warranted.

\section{Acknowledgements}

The author would like to acknowledge Paul Griffiths and Doug Orr of Precision Castparts Corporation for their trust and patience in supporting this project. Thanks to Steve Sikkenga at CannonMuskegon Corporation and Jeff Marksthaler at the BodyCote Materials Testing Laboratory in Portland, Oregon for their generous assistance in materials testing support. Noah Third, Precision Castparts Corporation, Dr. Ganjiang Feng, GE Power Systems and Dr. Ruel (Tony) Overfelt, Auburn University are acknowledged for our many invaluable metallurgical discussions and debates.

\section{References}

[1] Chester Sims, Norman Stoloff, William Hagel, Superalloys II (New York, NY: John Wiley \& Sons, Inc., 1987), 136-162.

[2] J.R. Davis, ed., Alloying: Understanding the Basics, (Materials Park, OH: ASM International, 2001), 540-548.

[3] Claudia Burton, "Differential Thermal Analysis and the Mechanisms of Minor Additions in Superalloys", Superalloys 1976, ed. D.R. Muzyka et al. (TMS, 1976), 147-158

[4] J. Lecomte-Beckers, "Relation Between Chemistry, Solidification Behaviour, Microstructure and Microporosity in Nickel-base Superalloys”, Superalloys 1988, (TMS, 1988), 713722

[5] John Campbell, Castings (Jordan Hill, Oxford: Elsevier Ltd., 2003), 205-259

[6] C.P. Sullivan, J.D. Varin and M.J. Donachie, Jr., "Relationship of Properties to Microstructure in Cobalt Base Superalloys", Metals Engineering Quarterly, 9 (2) (1969), 16-28.

[7] M.F. Rothman, R.D. Zordan, "Role of Refractory Elements in Cobalt-Base Alloys", Refractory Alloying Elements in Superalloys, ed., J.K. Tien and S. Reichman, (ASM, 1984), 101115 .

[8] W.V. Youdelis and O. Kwon, "Carbide phases in cobalt base superalloy: role of nucleation entropy in refinement", Metal Science, 17 (8) (1983), 379-384.

[9] Michael E. Brown, Introduction to Thermal Analysis (Dordrecht, The Netherlands: Kluwer Academic Publishers, 2001), 55-87.

[10] Dr. R. Boyles, private conversation with the author, PCC Structurals Inc., 13 July 2007

[11] JMP ${ }^{\mathrm{TM}}$ Statistics \& Graphics Guide (Cary, NC: SAS Institute, Inc., 2002)

[12] K.P. Ronan, "FSX-414 Characterization Project Update" (Report Phase I - Update 2, PCC Structurals Inc., 2004)

[13] George F. Vander Voort, ed., ASM Handbook Volume 9: Metallography and Microstructures, (Materials Park, OH: ASM International, 2004), 762-774, 834-851 